\title{
Factores generadores de la disminución del turismo y afectaciones posteriores, zona costera Acapulco, México
}

\author{
Factors causing a decrease in tourism in the Acapulco coastal \\ zone, Mexico, and subsequent effects.
}

\author{
Oscar Daniel Rivera-González ${ }^{1}$ \\ Universidad Nacional Autónoma de México, México
}

\begin{abstract}
Resumen
El siguiente artículo de investigación analiza la disminución del turismo nacional e internacional a lo largo de la zona Costera de Acapulco, originándose adversidades para los pobladores que sostienen su economía con base en dicha actividad y en la derrama económica del mismo. Actualmente con base en la teoría y empiría de la investigación existe una disminución considerable del turismo el cual que va en aumento, dicha información es ratificada y cuantificada con base en entrevistas formales a los habitantes y turistas, puntualizando que el crecimiento urbano desmedido y no regulado en las primeras fases del mismo es uno de los desencadenantes de dicha problemática, lo cual da como resultado aumento de basura, contaminación, inseguridad, violencia y diversas causas que se mencionan a lo largo del artículo. La inacción e indiferencia en mayor parte del Gobierno Municipal de Acapulco y del Estatal de Guerrero, mismos que incentivan las problemáticas antes mencionadas, por lo anterior se proponen medidas urgentes a dicha disminución en el puerto de Acapulco, aplicarse de manera urgente y eficaz siempre tomando en cuenta a la población ya que de lo contrario será muy probablemente en un futuro cercano un puerto olvidado y poco visitado.
\end{abstract}

Palabras clave: Disminución, turismo, afectaciones, habitantes, contaminación, violencia.

1 Licenciado en Geografía. Universidad Nacional autónoma de México (UNAM). Especialista en Economía Ambiental y Ecológica UNAM. Maestro en Urbanismo UNAM. Estudiante 5to semestre y Candidato a Doctor en Urbanismo. UNAM. Correo electrónico: oscardanieldanyboy@hotmail.com. (i) https://orcid.org/0000-0002-7698-7433 


\begin{abstract}
The following article analyzes the decrease in national and international tourism along the Acapulco coastal zone, causing adversities for inhabitants who sustain their economy on said activity and its economic contribution. Currently, based on theoretical and empirical research, a considerable decrease in tourism activity has been evidenced. This finding is ratified and quantified based on formal interviews with residents and tourists that point to excessive and unregulated early-stage urban growth as one triggering causative factor as it increases the generation of municipal solid waste, pollution, insecurity, violence and many other negative consequences mentioned throughout the article. The inaction and indifference of the authorities, mainly that of the Municipal Government of Acapulco and the Government of the State of Guerrero, encourage the progression of the aforementioned damaging issues. In view of the above, urgent measures are proposed to counter the deceleration of tourism in the port of Acapulco, which are to be applied urgently and effectively, with main consideration of the population, since otherwise it will become a forgotten and scantly visited port in the near future.
\end{abstract}

Keywords: Decrease; Tourism; Affectations; Inhabitants; Pollution; Violence.

\title{
Introducción
}

En México, se ubica el Estado de Guerrero (Figura 1) el cual se identifica al encontrarse el puerto de Acapulco, conocido turísticamente por su conformación cartográfica semicircular (Figura 2), además de ser reconocido mundialmente por sus playas y clima tropical.

El Estado de Guerrero, se sostiene en buena parte del turismo, sea nacional o internacional, el cual es un factor económico muy importante del cual viven muchos habitantes que se dedican al comercio turístico sobre la bahía y recomendado para pasar sus vacaciones al turismo en general por parte de las personas que visitaron el puerto por ser un lugar atractivo.

Sin embargo, a principios de este siglo XXI ha venido decayendo el turismo por diversas causas entre las que se encuentra la contaminación generada por la basura a lo largo de la zona costera por falta de infraestructura de información y concientización por parte de las autoridades del Municipio, por otro lado la ausencia de contenedores para su depósito, lo cual no previene a la población de arrojar sus desechos a la playa o en la vía publica; y además por el desahogo de las aguas negras en las que se incluyen las que producen las cadenas hoteleras, las cuales son arrojadas directamente al mar debido a la inadecuada planeación del drenaje originada por la inacción del gobierno federal, estatal y municipal en temas de ordenamiento territorial urbano. 
Oscar Daniel Rivera-González

Factores generadores de la disminución del turismo y afectaciones posteriores, zona costera Acapulco, México

Figura 1. República Mexicana y Estado de Guerrero, año 2020.

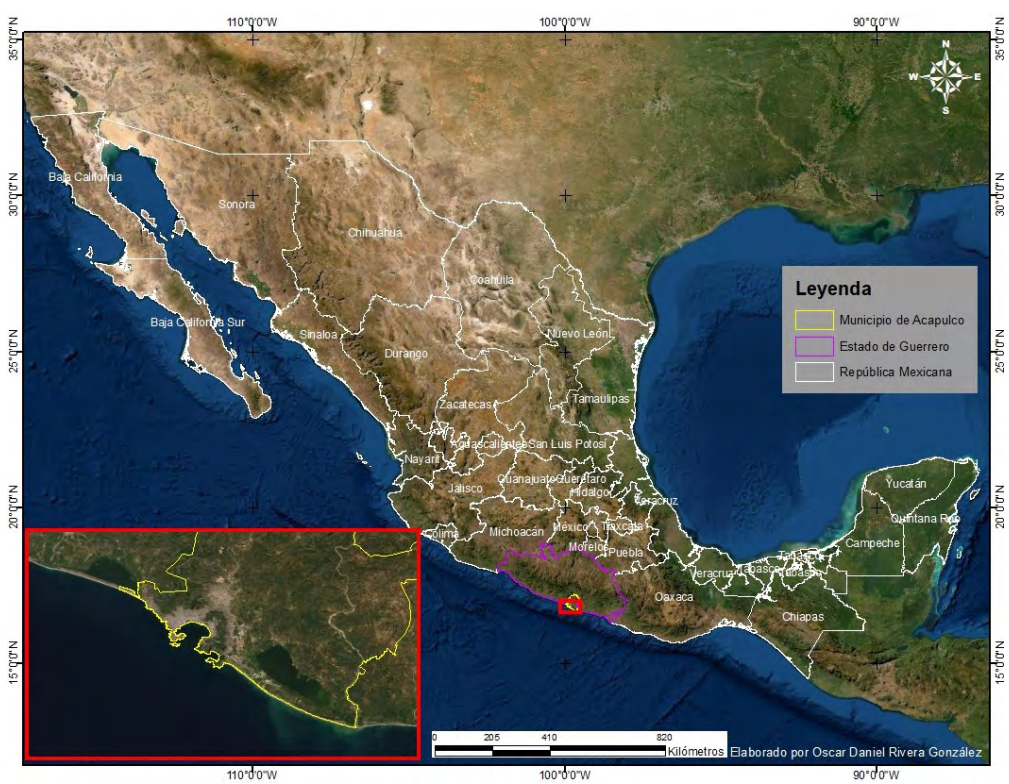

Fuente: Elaboración propia con Software SIG ArcGis.

Figura 2. Zona Costera de Acapulco y área de estudio, año 2020.

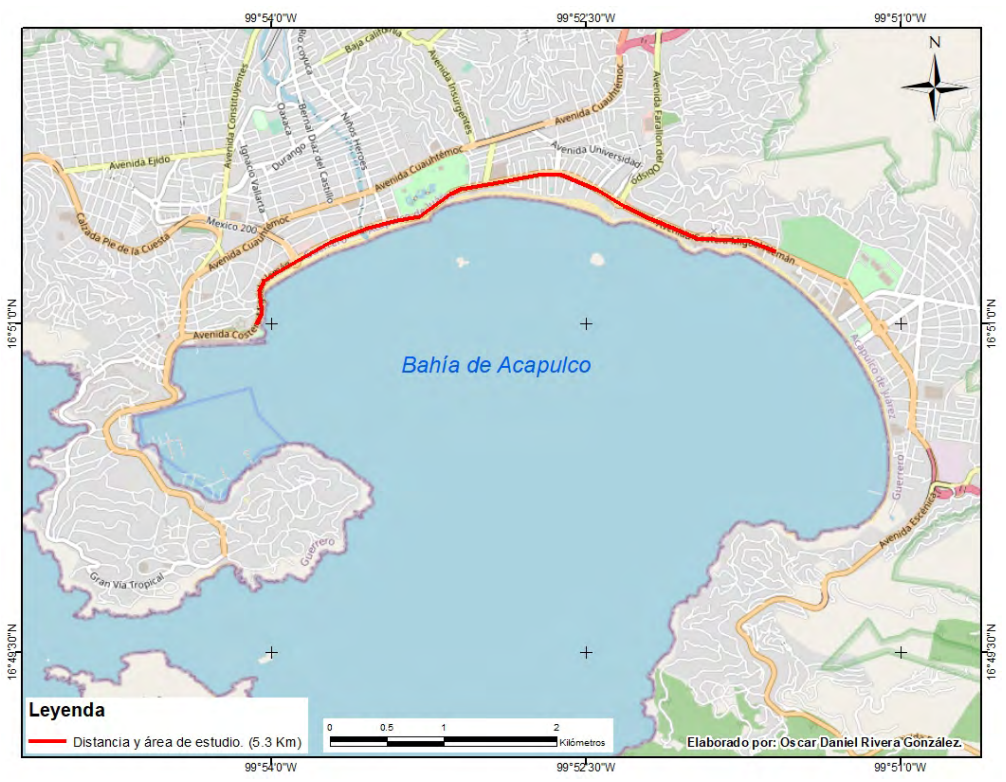

Fuente: Elaboración propia con Software SIG Arc Gis. 
Por otro lado el tema de la inseguridad para el turista, ya sea por robo o asaltos sobre la playa, así mismo muy recientemente confrontaciones entre diversas organizaciones criminales que generan un clima de incertidumbre entre los turista y habitantes, la suma de todas las problemáticas anteriores estarían relacionadas directamente a la nula gestión del gobierno en su tres niveles de gobierno para resolver las mismas, observándose solo poca organización con base en el trabajo teórico y empírico obtenido en el presente artículo.

\section{Marco Metodológico}

Se analizó el crecimiento urbano, con base en cartografía digitalizada por medio de Sistemas de Información Geográfica (SIG) para su fotointerpretación y evaluación del crecimiento urbano no regulado por parte de las autoridades gubernamentales en México.

Se realizaron visitas recientes al puerto de Acapulco, entre los meses de abril y mayo del año 2020 para interactuar de manera formal e informal y realizar algunas entrevistas con habitantes y turistas para obtener una percepción de ellos acerca de la problemática planteada, así como revisar las páginas web de los Gobiernos tanto el Estatal de Guerrero como el Municipal de Acapulco, referente a su infraestructura y procedimientos de Gobierno para cumplir sus acciones ejecutivas relacionadas con la referida problemática.

Se revisaron páginas electrónicas de los Ministerios Federales, relacionados con el turismo de manera general en la República Mexicana y en Acapulco en particular, así como de revisión minuciosa de periódicos y agencias noticiosas que aportaron información útil al objetivo trazado.

Finalmente, se consultaron teóricos y artículos internacionales que abordaron la problemática total o parcialmente planteada en el presente artículo de investigación, así como una revisión general del estado del arte en donde estriba y refiere dicha problemática.

\section{Marco teórico}

Es de suma importancia, relacionar el sistema teórico con lo ya conocido parcialmente en la realidad encontrada en el trabajo empírico, primeramente comprendiendo y aplicando lo conocido, comprendido que el pensamiento humano es importante para poder utilizarlo de manera 
correcta y fundamentada en cuestiones y soluciones reales, relacionándolo siempre con la disminución del turismo en el puerto de Acapulco y así sea benéfico para la población que se mantiene económicamente debido al turismo nacional e internacional.

El turismo, forma parte de uno de los principales sectores económicos a nivel mundial, siendo objeto de estudio en diversos destinos geográficos. Esta actividad económica opera como fuente de oportunidades para la modernización socioeconómica y cultural de un área geográfica, siendo el patrimonio un factor de cohesión social por las importantes sensibilidades a las que afecta. En consecuencia, son más frecuentes los modelos que giran en torno al desarrollo sostenible del turismo de un destino (Orgaz y Moral, 2016).

La cita anterior, tiene demasiada relevancia ya que expone la cuestión económica en cuanto a su estrecha relación con la forma o estructura de la geografía en alguna zona turística, es por ello que deberán modernizarse dichas zonas hasta cierto punto rurales para ser más atractivo para los paseantes internacionales, sin embargo no se deberá caer en la construcción y urbanismo voraz en zonas de playa o de descanso, por lo que será vital el tema de la sostenibilidad en cuanto al cuidado de los recursos naturales como lo puede ser el mar, arena, vegetación, flora, fauna, entre otros recursos no renovables con base en el grado de explotación o sobreexplotación, dicha sostenibilidad deberá ser gestionada desde el aparato gubernamental en este caso el Municipio de Acapulco dirigido y explicado a la población y por consiguiente reflejado en el turismo.

El mercado turístico se ha buscado explicar de diversas maneras al contabilizar el porcentaje de turistas que regresan satisfechos a su lugar de origen, pero sin detenerse a explicar de una manera más puntual las consecuencias personales de tal satisfacción, lo cual está asociado con el impacto que la satisfacción tiene en su campo de la experiencia. Sin ese conocimiento cualquier política de mercado deja de escudriñar metodológicamente el campo de la experiencia (realidad experiencial inmediata) del turista al momento que se encontraba en el Puerto de Acapulco, viviendo una realidad distinta a la que vive todos los días (Guerrero et al., 2009).

La mención anterior es de vital importancia comprenderla y examinarla, ya que el mercado turístico es influenciado mayormente por la mercadotecnia y popularidad de ciertas zonas costeras en México sin embargo, 
la vivencia por parte de turistas nacionales y extranjeros conocidos como emisores, mismos que darán a conocer la vivencia y/o experiencia a favor o en contra del destino turístico quedando en la memoria del turista y muy probablemente en el pensamiento de receptor de dicha historia de vivencia explicada por parte del turista, lo que a su vez se convertirá en la réplica de una memoria buena o mala de un destino turístico que muy probablemente ni siquiera conoce el receptor o posible turista, por lo anterior es de suma importancia el cuidado al turista en general por parte del Gobierno Estatal de Guerrero y Municipal de Acapulco.

Es necesario replantear enfoques, metodologías y modelos para disminuir la presión ejercida por el turismo tradicional que amenaza la estabilidad de la actividad y el patrimonio ambiental y cultural, especialmente, en las áreas rurales (Del Valle, 2017).

El culpar al turismo del desgaste de un destino turístico sería un error hasta cierto punto, por lo cual el aparato Municipal de Acapulco deberá diseñar mecanismos de coordinación y gestión entre turistas y pobladores cuidando el espacio geográfico natural de la zona costera, algo crucial es que un alto porcentaje del turismo visita playas mexicanas para el olvido de las ciudades en las cuales ellos habitan, con base en ello gustan de visitar zonas rurales naturales de playa.

Acapulco actualmente, parece más una ciudad en crecimiento con costa marina que un puerto natural en zona de playa, esta transformación impacta en gran porcentaje la baja del turismo, lo cual podría ser reestructurado ruralmente-urbanísticamente respetando las zonas naturales algo que al parecer el gobierno mexicano no ha comprendido en cuanto a que no siempre el urbanismo es sinónimo de confort o de bienestar.

Con frecuencia, el potencial visitante se enfrenta a la tarea de conciliar la imagen negativa a la que contribuye la difusión periodística y televisiva de hechos de violencia en un destino turístico, con el marketing publicitario que al mismo tiempo promueven los sectores que se benefician con estas actividades en los mismos destinos (De la Torre y Navarrete, 2013).

La cita anterior estriba en el cuidado de la imagen del puerto entre los medios televisivos y más aun con las redes sociales, es por ello la urgencia de la adecuada gestión política entre el gobierno Municipal y Estatal con la población, para que los hechos de violencia de cualquier tipo que se han vivido en los últimos años en el puerto afecten en menor 
manera a los turistas, con base en entrevistas formales con algunos turistas nacionales y extranjeros (figura 3 y 4 ) temen el acudir al puerto de Acapulco por distintos tipos de violencia e inseguridad que sufre la zona costera actualmente y que ellos son ajenos a esta problemática teniendo que buscar opciones en otros Estados de la República Mexicana u otros países para el disfrute y tranquilidad de ellos y su familia.

Figura 3. Zona costera de Acapulco. Entrevista a turistas nacionales. Datos absolutos, 2020.

¿Teme por su seguridad por algun tipo de violencia?

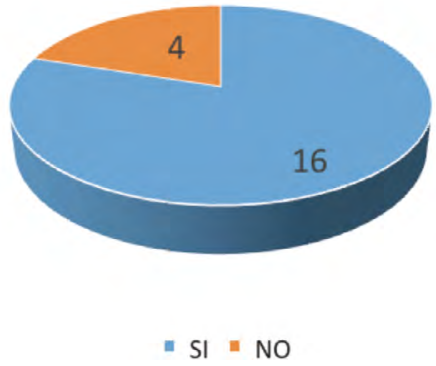

Fuente: Elaboración propia con base en visitas a campo fecha $20 /$ abril $/ 2020$.

Figura 4. Zona costera de Acapulco. Entrevista a turistas extranjeros. Datos absolutos, 2020 ¿Teme por su seguridad por algún tipo de violencia?

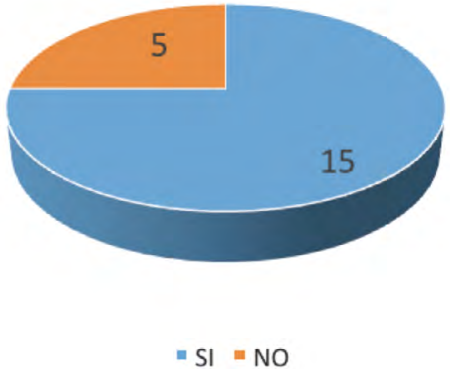

Fuente: Elaboración propia con base en visitas a campo fecha $20 /$ abril/2020.
En este contexto, la relación turismo y criminalidad, representa un tema nuevo y sensible de la investigación en muchos destinos, ya que, las autoridades se resisten a medir y posiblemente arriesgarse a revelar el nivel de delincuencia debido a la amenaza que representa para el futuro desarrollo de esta actividad en su localidad (Schiebler et al., 1996).

Los niveles de delincuencia que han acontecido en los últimos años en la zona costera de Acapulco deben ser sin duda gestionados por los tres niveles de gobierno en México con mucha precaución de no acrecentar más la vulnerabilidad y peligro que viven los turistas y los mismos pobladores, primeramente se le deberá dotar de seguridad y bienestar a los habitantes del puerto para que posteriormente sea replicado en el turismo nacional e internacional, lo cual podría darse de manera gradual dado el nivel de violencia en los últimos años tan abismal y creciente, de no proponer una solución real y aplicable muy 
probablemente no aumenten los niveles de criminalidad pero persistirá el temor por parte del turismo el cual difícilmente asistirá a pasar sus vacaciones en el puerto de Acapulco.

Nuestro estudio aborda los problemas de sostenibilidad del desarrollo turístico de una ciudad como la de Acapulco, donde se experimenta un desarrollo desigual y excluyente; enfocándonos en los espacios periurbanos donde el deterioro ambiental y la contaminación son consustanciales a la escasez de servicios y a la presencia de pobreza (López et al., 2012).

El tema del deterioro ambiental o contaminación ambiental como lo menciona la cita pasada es algo que hay que explorar y entender de manera concisa, es por ello que el tema de la sostenibilidad es muy importante el cual debe ser entendido por las autoridades gubernamentales para su explicación y aplicación con los habitantes, inclusive será directamente proporcional al gusto y disfrute por parte de los turistas.

La operación de mecanismos de cuidado ambiental o de sostenibilidad entendiéndose como las características de desarrollo en cualquier vertiente que asegura las necesidades del presente sin comprometer de ninguna manera las necesidades de futuras generaciones, para que sigan prevaleciendo y existiendo una ganancia entre el turismo y la población la cual es de vital importancia, realizando gestión y concertación del aparato gubernamental enfocado a la población, lo que dará resultados para minimizar o al menos combatir el grado de presencia de pobreza en la población que se sostiene del turismo.

Se constató que el turismo no planeado se convierte en un obstáculo para un desarrollo sustentable; Acapulco es un ejemplo de ello, pues en él se reproducen las asimetrías socioeconómicas que impiden un desarrollo integral. De igual manera, como en otras latitudes, en Acapulco el turismo enfrenta dos alternativas: la sustentabilidad o la modernidad globalizadora, un reto de difícil integración en nuestro país, debido a la pobreza existente y a las dificultades para impulsar un crecimiento equilibrado, el cual es hoy por hoy una prioridad indiscutible (López et al., 2012).

El tema de la globalización en México y en todos sus Estados es prácticamente imposible no considerarlo, el camino de interacción entre los habitantes y las empresas extranjeras con el gobierno mexicano da como resultado un soporte económico hasta cierto punto adecuado, talvez no sea el ideal para las familias que sufren de pobreza extrema en zonas rurales del puerto de Acapulco. 
Sin embargo, deberá combatirse el tema de la marginación con apoyo del desarrollo sustentable y sostenible de la naturaleza ya que es la única que podrá proveer un escenario de confort y disfrute para el turismo extranjero y nacional, como ya se ha mencionado en párrafos anteriores deberá generar el aparato gubernamental mexicano coordinación, gestión, concertación, concientización entre la población, empresas en este caso las cadenas hoteleras, restaurantes a lo largo de la costera y agencias de viajes, sin dejar nunca de lado el otorgar empleos con adecuada remuneración económica a los habitantes del puerto ya que son los más vulnerables ante la falta de turismo o disminución del mismo.

El destino turístico se convierte en el gran generador de diversas experiencias a partir del consumo, en donde el conjunto de atributos, productos, servicios, etc. se convierten en oportunidades de disfrutar el lugar visitado. Pero para que esto se logre, el destino deberá otorgarles todas las facilidades a los consumidores como cualquier otro producto de consumo, considerando elementos como el coste de la experiencia del turista, la calidad del servicio que recibe, la atención del personal hacia el cliente, y el reconocimiento social que la experiencia le generará (Solís et al., 2016).

La última cita del presente apartado menciona algo muy interesante e integrador en cuanto a la estadía del turista en algún lugar en este caso en el puerto de Acapulco, el Gobierno Mexicano junto con los habitantes deberán darle seguridad al paseante y el lugar en si por su geografía y naturaleza dará el confort y disfrute al turista, esto será de gran relevancia ya que los mismos turistas recomendarán al puerto con base en lo que acontecieron de bienestar o por el contrario denostarán o deshonrarán al lugar ante otros familiares o gente conocida en general y más aún distribuirlo entre los diferentes medios de redes sociales, los cuales permean en cualquier tipo de sociedad en algún lugar del mundo.

\section{Historia y antecedentes turísticos en la zona costera de Acapulco}

Los periodos en los que se divide las diferentes etapas del turismo en dicho puerto, así como su interacción con el ambiente y turismo derivan de lo siguiente.

El primero de 1927-1954, en este periodo se observó un gran despliegue de actividad turística, el segundo de 1955-1971 se caracteriza por su auge turístico y el tercero de 1972-1985 en el cual se dio el estancamiento 
en diferentes vertientes por la aplicación de medidas correctivas que en ese entonces empleaba el Municipio.

Estos factores son: a) el suelo urbano, en el primer periodo, b) la estructura urbana, en el segundo, y c) la contaminación en el tercero (Ramírez, 1989, p. 138).

De esta manera en el primer periodo se observa la relación que se da entre el centro vacacional y el suelo urbano por el desarrollo de la estructura urbana y por último la actividad turística y su impacto en el ambiente, no existiendo hasta este momento problemática con el turismo.

En el caso del segundo periodo se observa la estrecha relación entre turismo y medio ambiente, la actividad turística afectó directamente a la naturaleza por la gran transformación que se da al entorno para que el turismo se sienta mejor y atraer al mismo, afectando al medio geográfico natural a través de la transformación de la estructura rural con crecimiento urbano voraz y que en la actualidad se encuentra muy descuidado observándose los inicios de la disminución el turismo en Acapulco sin ser todavía tan evidente.

La actividad turística que desde sus inicios en el puerto se observó con base en las transformaciones que realizó el Municipio en el entorno natural con el paso de los años y hasta la actualidad, afectó evidentemente al medio ambiente y más aun sin una adecuada organización del Municipio de Acapulco lo que derivó en algún porcentaje el estancamiento turístico y económico.

Se aperturó una gran actividad turística en el puerto, principalmente por residentes del Distrito Federal ahora Ciudad de México (CDMX) por lo que se observó con el paso de los años un gran desarrollo urbano y turístico. Se tienen registros que se dio un resurgimiento de un llamado puerto olvidado, ya que después de la Independencia de México respecto de España en el año de 1821, se cancelaron los lazos marítimos entre Acapulco y Manila, esto dio al puerto un estancamiento y quedó como un puerto olvidado por algunos años.

En noviembre de 1927 se construye la carretera de Acapulco-Taxco y con esto se rompe el aislamiento que tenía el puerto a través de la conexión y visita de turismo residente en Cuernavaca y en el Distrito Federal ahora CDMX. De esta manera fue posible que turistas nacionales e internacionales descubrieran la gran belleza que tenía el puerto y así con el 
tiempo convirtiéndolo en el puerto más visitado de México, más aún con el aeropuerto que se construyó en el año de 1928.

Las primeras construcciones sobre la Zona Costera datan de 1934, al igual que en la década de los años 30s, también se construyen los primeros hoteles y en el año de 1944 se construyen otros más. Un factor crucial por el cual se empezó a realizar la construcción de la zona hotelera fue una campaña que realizó el presidente de México Manuel Ávila Camacho, campaña que tituló "peso contra peso"; esta gran campaña trataba de que México debía aportar una cantidad igual a la que el llamado capital extranjero invertía.

La forma geográfica de la zona costera se fue modificando, la parte rural se transformó en zonas residenciales, se empezaron a trazar calles por lo que se afectaron varias playas como la principal llamada Zona La Costera, cabe mencionar que el presidente Miguel Alemán Valdez en su mandato de 1946-1952 fue el fundador de la cadena hotelera llamada Continental quien además llamó a la Zona Costera con su nombre.

La historia del despliegue turístico en Acapulco, no fue tan perjudicial para el crecimiento urbano no regulado, más bien fue la poca gestión y amplia generación de ganancias económicas otorgadas por el capital extranjero por medio de sus turistas, dando como resultado la nula atención y cuidado de la parte natural rural del puerto mismo por parte de habitantes y gobierno en México, observándose el crecimiento de contaminación y construcción de cadenas hoteleras sin una regulación ambiental aconteciendo desechos de los hoteles vertidos al mar y que hasta la actualidad prevalece dicha contaminación, aunado al grado de violencia de cualquier tipo que acontece en la actualidad, es por ello el gran porcentaje de disminución del turismo en el puerto acapulqueño.

\section{Zona costera y transformación urbana}

El puerto de Acapulco fue aconteciendo varias transformaciones urbanas y de construcciones no reguladas (figura 5 y 6 ) incentivadas con la ausencia de políticas públicas encargadas de gestión urbana, observándose un urbanismo voraz mismo que afectó la imagen natural y cuidado del puerto de Acapulco. 
Figura 5. Límite Urbano en la Zona Costera de Acapulco, años 1993 y 2003.

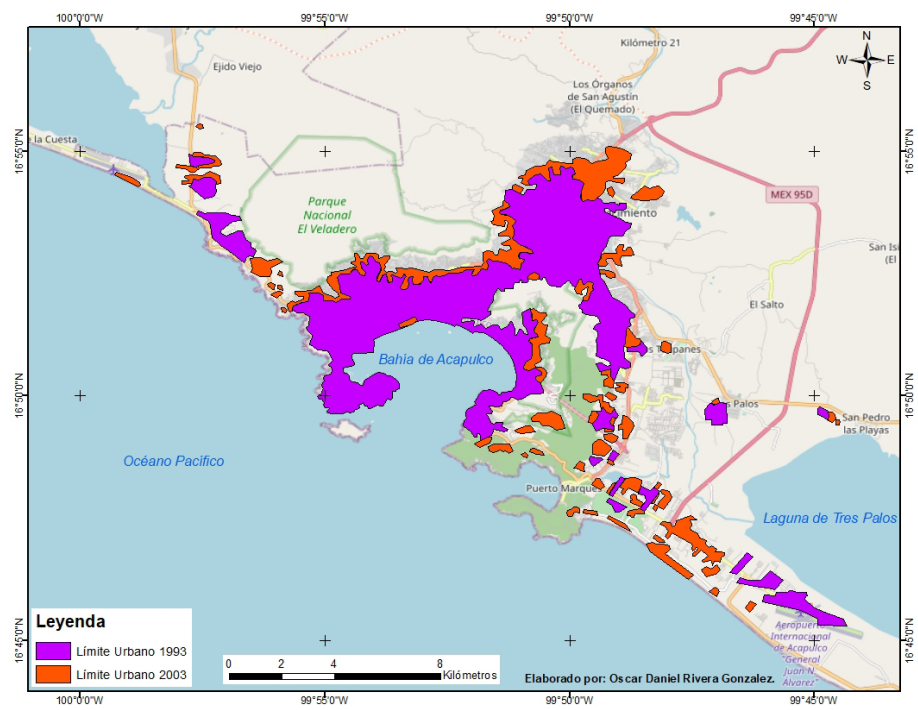

Fuente: Elaboración propia con datos del Instituto Nacional de Estadística y Geografía (INEGI), Software Surfer 13 y Global Mapper.

Figura 6. Límite Urbano en la Zona Costera de Acapulco, año 2020.

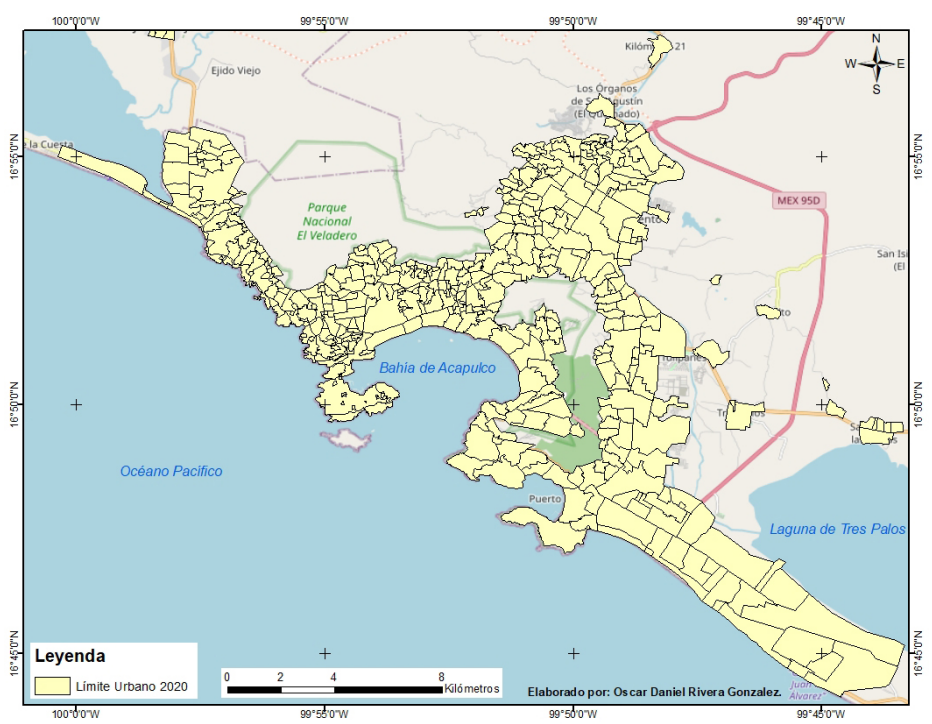

Fuente: Elaboración propia con datos del Instituto Nacional de Estadística y Geografía (INEGI) e imágenes satelitales, Software Arc Gis. 
El Gobierno Mexicano en años pasados, aproximadamente alrededor de 1940 se observó que el uso agrícola ya no tenía tanta importancia, no interesando que bastante población vivía de esa actividad agrícola, así que continuó urbanizando la Zona Costera para seguir obteniendo cada vez más ganancias con la construcción de cadenas hoteleras cambiando el uso de suelo.

El 9 de noviembre del año 1940, el presidente de México en aquel entonces Lázaro Cárdenas, expropió 76 hectáreas de 726 mismas que corrían sobre la Zona Costera, construyéndose grandes hoteles como los que a la fecha prevalecen entre los cuales se encuentran Playa Sol, Hotel Holiday Inn y Hotel las Torres Gemelas.

Posteriormente, en varios terrenos ejidales se construyó la zona residencial Costa Azul que a la fecha sigue vigente, cabe mencionar que en la parte final de dichos terrenos se encontraba un cementerio el cual fue destruido en el año 1960, espacio utilizado para la construcción de hoteles.

En líneas anteriores, se observa que el Gobierno Municipal, Estatal y Federal, no reguló u ordenó la situación en la que se construyeron cadenas hoteleras para el beneficio de sus habitantes, por consiguiente los únicos que ganaron y siguen ganando a la fecha generando grandes volúmenes económicos son los dueños de dichas cadenas hoteleras, contrario a la población lugareña la cual vive en condiciones de pobreza incluso pobreza extrema, observándose esta situación en la zona de la entrada al puerto de Acapulco que va de la CDMX al puerto por la autopista del Sol hasta la entrada al Maxitunel existiendo condiciones de plusvalía muy baja (figura 7).

Figura 7. Imagen grado de vulnerabilidad económica y social en la parte Norte de la Zona Costera de Acapulco Guerrero, México.

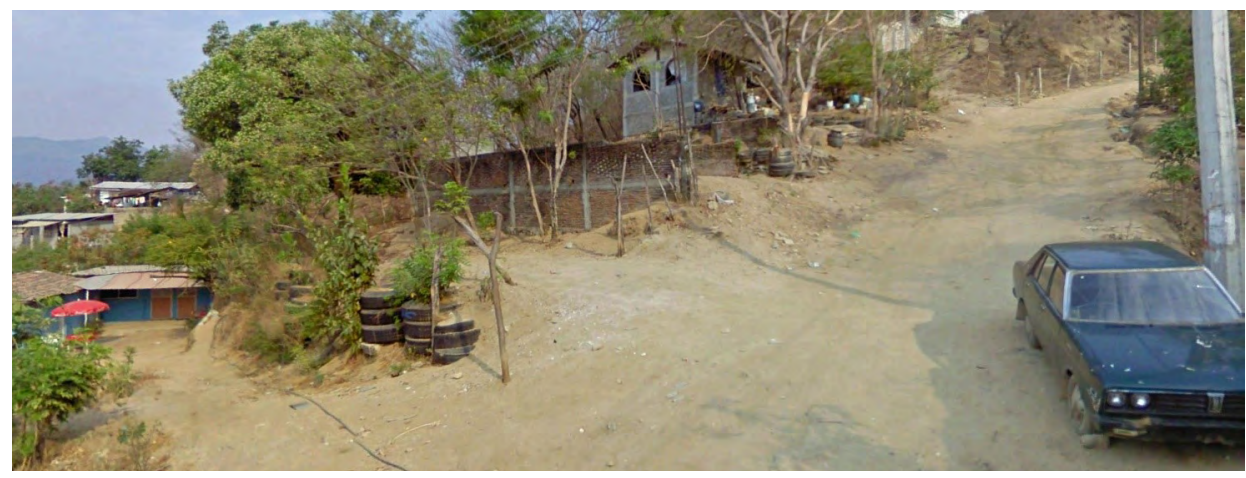

Fuente: Google Earth Pro, 2020. 
La mayor parte de las población vive del turismo nacional e internacional, vendiendo productos en la Zona Costera los cuales son, fruta, verdura, quesadillas, pescado, entre otros, puntualizando que dicha venta se realiza con una higiene poco adecuada debido a las condiciones de pobreza lo cual es proporcional a la ausencia de sanidad (figura 8), confirmando que la construcción de cadenas hoteleras benefició poco a los habitantes del puerto obteniendo solo trabajo para sobrevivir.

Figura 8. Imagen venta informal de productos sobre la Costera de Acapulco.

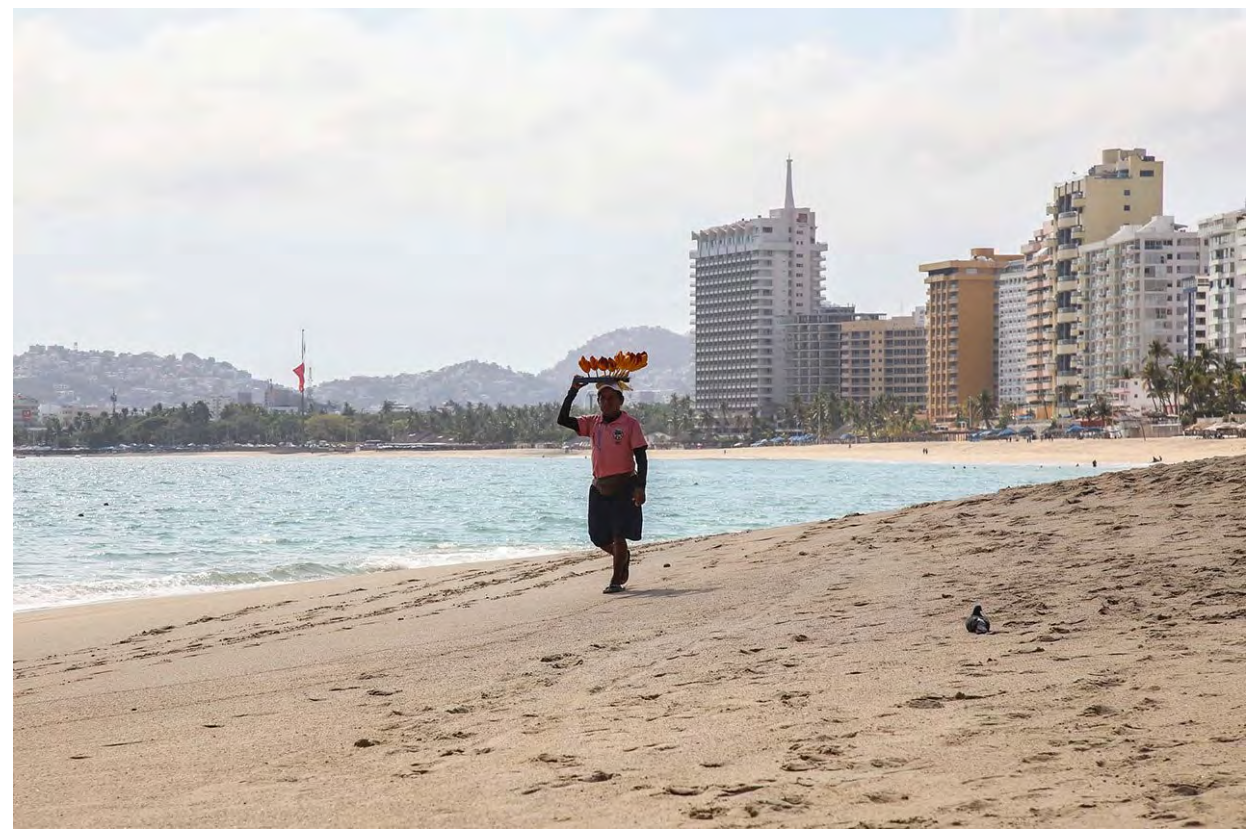

Fuente: Revista en línea FORBES, recuperado de https://www.forbes.com.mx/economia-acapulco-abre-turismo-despues-confinamiento/, fecha de consulta 2 de mayo del 2020.

Lo anterior es reforzado con la siguiente cita:

El crecimiento de Acapulco se produce en poco tiempo, de tal manera que la urbanización se produjo espontáneamente, sin una orientación previa. La población se encontró en situaciones difíciles, porque los servicios no operaron al mismo ritmo y los esporádicos paliativos gubernamentales estuvieron carentes de ejes que articularan políticas coherentes de desarrollo y bienestar acordes al contexto (Mombelli, 2011, p.6). 
Es por lo anterior que al perecer el bienestar de los habitantes del puerto es el menos observado y atendido, el gobierno municipal tiene algún grado de culpabilidad ya que no se resuelven en la actualidad las condiciones de vida digna que cualquier ser humano debería tener y más aún en un puerto tan reconocido internacionalmente, en la actualidad según el trabajo empírico sigue el aparato gubernamental carente de ejes articuladores de políticas públicas orientadas a beneficiar a los habitantes de la misma manera que al turista.

Figura 9. Zona costera de Acapulco. Entrevista a habitantes. Datos absolutos, 2020.

¿Sabe usted de quienes eran originalmente las tierras donde actualmente se encuentra la zona hotelera?

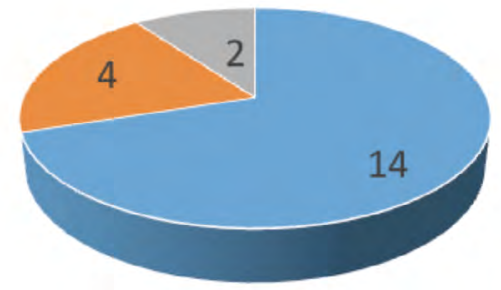

- De los campesinos Del Gobierno $=$ De nadie

Fuente: Elaboración propia con base en visitas a campo fecha $20 /$ abril/2020.

Hyatt Internacional, Continetal Hilton, Wester International Hotels, Princess Hotel International, Marriot, Holiday Inn, Melia, cadenas hoteleras que desde que se instauraron en la Zona Costera hasta hoy, buscan cuidar la integridad del huésped mas no la del turista en general, ya que la mayoría de estos hoteles, instalan en la zona de playa frente a ellos anuncios y en ocasiones límites con cuerdas para que el huésped no se introduzca más allá de la zona que el hotel determina.

Con base en la problemática anterior, el Municipio deberá instaurar un plan debidamente gestionado y coordinarse con todas las cadenas hoteleras que se encuentran en la Costera para que cuiden no solo al que 
Figura 10. Zona costera de Acapulco. Entrevista a turistas. Datos absolutos, 2020.

¿Le parece elevado el precio por hospedarse en un hotel sobre la zona costera?

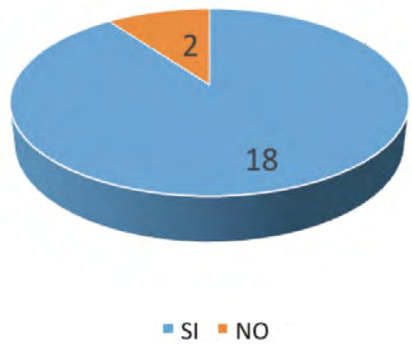

Fuente: Elaboración propia con base en visitas a campo fecha 20/abril/2020.

Figura 11. Zona costera de Acapulco. Entrevista a turistas. Datos absolutos en pesos mexicanos, 2020.

¿Cuál es el costo aproximado por hospedarse en el hotel de su preferencia a lo largo de la zona costera?

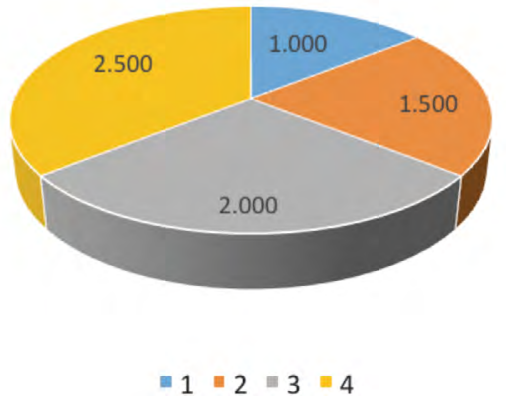

Fuente: Elaboración propia con base en visitas a campo fecha 20/abril/2020.

se hospeda en el hotel, también proteger a los turistas y habitantes que se encuentran en la zona de mar y arena frente a la construcción hotelera..

La mayoría de las cadenas hoteleras a lo largo de la zona costera se posesionan del área de mar y arena que les corresponde según ellos, inclusive muchos de los hoteles cercan y limitan esta área con rocas, cuerdas u otro tipo de material, no permitiendo pasar a otros turistas e inclusive a los mismos habitantes que desean pasar a vender sus productos al turismo.

Es importante mencionar que la mayor parte de los hoteles desde hace varios años han dado trabajo a las personas habitantes de Acapulco, sin embargo son trabajos no muy bien remunerados, empleos de afanadoras, meseros, animadores, cantineros, salvavidas entre otros, contrastando con los precios que estas cadenas hoteleras ofrecen a los viajeros los cuales son elevados según entrevistas con turistas (figura 10 y 11) al hospedarse una noche aproximadamente el costo oscila entre los 1,400 y 2,500 pesos, los que pueden pagar esos precios en su mayoría son turistas extranjeros.

Con base en lo anterior deberían dar más oportunidades de beneficio a los habitantes y con un mejor suelo, ya que estas grandes cadenas hoteleras obtienen grandes ganancias al año al estar instaurados en un gran 
puerto turístico conocido a nivel mundial, sin embargo este problema se podría solucionar si el Gobierno del Estado de Guerrero pusiera un alto a estas injusticias.

Complementando las gráficas anteriores, según un habitante mismo que es taxista del puerto de Acapulco, menciona que el Gobierno Municipal tiene pensado elaborar un plan para que el Acapulco de antaño que tenía una imagen tipo pueblo y que era lo que atraía a los turistas, se retomará para regresar la imagen que anteriormente tenía la Zona Costera con un paisaje más rural-natural.

Una circunstancia que favoreció el surgimiento de Acapulco como centro turístico mundial, fue la clausura de uno de los puntos de atracción del turismo internacional (sobre todo para el vacacionista norteamericano), es decir, La Habana, después del triunfo de la revolución en Cuba (1959) y la ruptura de relaciones con Estados Unidos (Ramírez, 1989, p.143).

Lo anterior, fue un gran suceso que dio un fuerte impulso para que el vacacionista, en este caso norteamericano, observara la gran belleza e importancia del puerto de Acapulco y que hasta el día de hoy tiene dicha relevancia, todo esto se reafirma debido a la cercanía que tiene Estados Unidos con Acapulco y a la creación del nuevo aeropuerto internacional en el año de 1964 donde los aviones que se tenían en operación tipo jet, facilitaban el camino al norteamericano y con ello el disfrute que obtenía los habitantes de Estados Unidos con costos que para ellos son relativamente económicos tanto en transporte, hospedaje y consumo.

\section{Acapulco de lo rural a lo urbano y sus repercusiones en la dismi- nución del turismo debido a la inacción del gobierno municipal}

Los años en los que se observó una gran transformación del paisaje y de la imagen del puerto fue entre 1955 a 1971, aunque claro cada año que pasaba a partir de aquel entonces se ven más transformaciones urbanas.

En los años 50's, se le dio un mayor peso a la ampliación de la vialidad nadie reguló la transformación del proyecto urbano y se dio una gran desarticulación. En cuanto a la vivienda se conoce que en el año de 1985 el déficit fue de 26,000 viviendas al que cada año que pasaba se acumulan 10,000 más.

En cuanto al abastecimiento del agua potable, el puerto de Acapulco cuenta con una gran problemática, la red hidráulica es insuficiente para abastecer tanto a la zona hotelera como a los pocos habitantes que tienen 
agua potable en sus hogares. En el puerto se han realizado demasiadas modificaciones urbanas, las cuales han solo favorecido a los huéspedes de las cadenas hoteleras, sin embargo, un alto porcentaje de las viviendas que no se encuentran sobre la Zona Costera no cuentan con una instalación de agua potable dentro de sus hogares debido al alto grado de marginación (figura 12) generando poca higiene y enfermedades gastrointestinales en la población, problemática que el Municipio deberá resolver.

Figura 12. Imagen grado de vulnerabilidad económica y social en la parte norte de la Zona Costera de Acapulco.

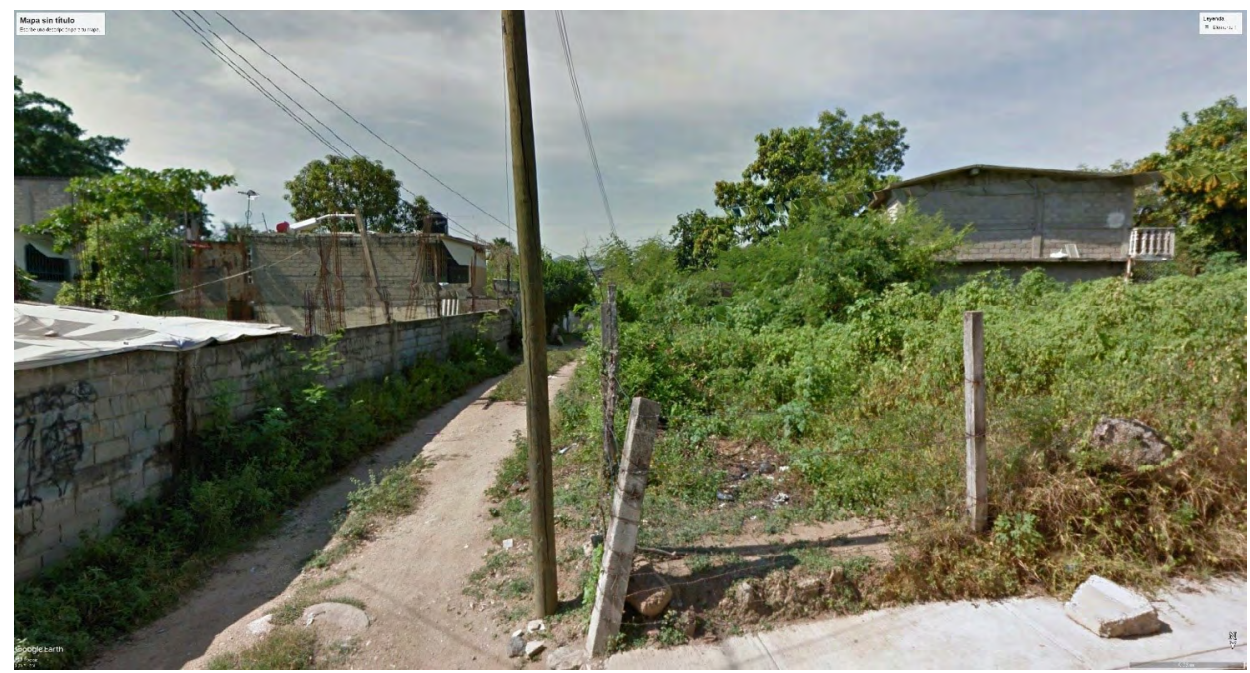

Fuente: Google Earth Pro, 2020.

El tema del actual Ordenamiento Territorial Urbano que gestiona el aparato Municipal del puerto, es poco claro en la teoría y muy evidente su falta de aplicación en beneficio de los habitantes y del turista en general en la empiría, ya que en la actualidad se sobreexplotan recursos naturales en el puerto de diversas maneras, puntualizando que aún es visitado el puerto de Acapulco por el turismo nacional e internacional sin embargo, cada año disminuye día tras día según encuestas a los habitantes del puerto (figura 13). 
Figura 13. Zona costera de Acapulco. Entrevista a habitantes.

Datos absolutos, 2020.

¿Ha disminuido el turismo en los últimos años?

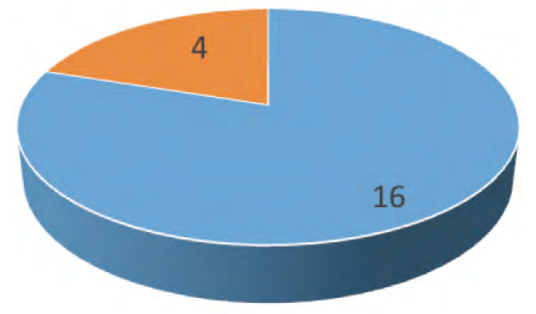

Fuente: Elaboración propia con base en visitas a campo fecha $12 /$ mayo/2020.
$=\mathrm{SI}=\mathrm{NO}$

Para comprender el contraste de la visitación al puerto de Acapulco y la disminución del turismo con base en las entrevistas (figura 13) y el ordenamiento territorial aplicado en la teoría y mostrado públicamente en la página electrónica oficial del Estado de Guerrero se observa lo siguiente.

Ordenamiento Territorial Urbano. Cuando se habla de los problemas urbanos en Acapulco generalmente se acepta que su origen está en la falta de planeación o en la mala planeación de la ciudad. El Plan Regional de Acapulco, reconoce que: Los problemas que se identifican es la falta de normatividad para el reordenamiento urbano y vivienda; e inexistencia de una entidad administrativa que dé seguimiento a la planeación urbana en el municipio, no se cumplen los ordenamientos legales en esta materia, los trámites a realizar por el ciudadano en este rubro son tediosos, los planes urbanos existentes están rebasados en tiempo y territorio.

A principios de abril de 2014, la presidencia municipal de Acapulco convocó a un grupo multidisciplinario de profesionistas y organizaciones de la sociedad civil para iniciar los trabajos de un nuevo Plan de Desarrollo Urbano para el Municipio, con base en talleres abiertos... (Programa Regional Acapulco, 2016, p.46).

La cita anterior muestra la problemática urbana misma que conoce casi perfectamente el Municipio del puerto, la falta de planeación es inadecuada según el mismo Municipio, los tramites a realizar por el ciudadano acapulqueño que atañen cuestiones urbanas son tediosas, es una verdad que inclusive se encuentra escrita en el Programa Regional de Acapulco, sin embargo solo se describe la problemática no se ataca o resuelve con mecanismos de gestión social entre el aparato gubernamental, hoteleros y población en general, esta última es la que más perece ante la falta de oportunidades y alto grado de marginación pese a ser todavía un puerto del cual el turismo nacional e internacional deja grandes derramas económicas 
de las cuales solo se beneficia el capital extranjero y hasta cierto punto el aparato gubernamental en cualquiera de sus tres niveles de gobierno.

En el caso de la derrama económica según datos proporcionados por el H. Ayuntamiento Constitucional de Acapulco con base en su portal electrónico oficial contrastan con la visitación y búsqueda de noticias periodísticas, mencionando el Ayuntamiento lo siguiente.

Durante el primer puente vacacional del año, más de 116 mil turistas nacionales y extranjeros que disfrutaron de Acapulco dejaron una derrama económica de 287 millones de pesos, informó el titular de la Secretaría de Turismo municipal. El funcionario reiteró en entrevista que Acapulco en materia turística inició con altas expectativas y se seguirá trabajando para mantener números altos en los siguientes días de cara a los próximos eventos culturales, deportivos y sociales que se realizarán en este destino de playa (Acapulco de Juárez, 2020).

La cita anterior contrasta con la realidad de las encuestas (figura 13) y con las noticias dos, tres y cuatro, mismas que se muestran más adelante, recomendado al lector realizar la lectura de las mismas para comparar la disminución del turismo en el puerto, inclusive al analizar la mención del Secretario de Turismo Municipal de Acapulco en la cita anterior, menciona que trabajarán más para mantener números altos en materia turística, exhibiendo la problemática de mantener un turismo relativamente alto para el gobierno municipal, observándose la inminente disminución del turista nacional o extranjero y afectaciones posteriores lo cual es tema central del presente artículo de investigación.

En el caso del ingreso obtenido por la remuneración económica del trabajo realizado por los habitantes del puerto de Acapulco, en diferentes actividades económicas según fuentes periodísticas e investigaciones formales, contrasta la información obtenida de las encuestas realizadas en la visitación al puerto de Acapulco (figura 10 y 11) en cuanto al elevado costo que generan las cadenas hoteleras por noche al turismo nacional e internacional lo cual no es proporcional al ingreso obtenido por los trabajadores originario del puerto, inclusive algo importante de mencionar es que según la siguiente cita el puerto de Acapulco y Tlaxcala son los peores lugares en toda la República Mexicana para laborar con base en el sueldo que reciben los trabajadores oriundos de dichos lugares, algo que es alarmante lo cual debería ser prioritario para el gobierno mexicano Federal, Estatal 
de Guerrero y Municipal de Acapulco con el fin de atenuar o desaparecer dicha disparidad, confirmando todo lo anterior con lo siguiente mención.

Las zonas metropolitanas con la tasa de condiciones críticas de ocupación (TCCO) más alta fueron, al cierre de junio, Tlaxcala $(21.3 \%$ de los ocupados), Tuxtla Gutiérrez (21.6\%) y Acapulco (21.9 por ciento). La TCCO incluye a las personas que se encuentran trabajando menos de 35 horas a la semana por razones ajenas a sus decisiones, más las que laboran más de 35 horas semanales con ingresos mensuales inferiores al salario mínimo y las que se emplean más de 48 horas semanales ganando hasta dos salarios mínimos.

La investigadora de la UNAM agregó que Acapulco es una ciudad ubicada en un estado con altos índices de pobreza y violencia, que han mermado la industria turística, "hay personas que trabajan muchas horas a cambio de un salario muy bajo y que viven en lugares con alta afluencia delictiva (E1 Economista, 2018).

La mención y cita anterior demuestra la inoperancia del aparato $\mathrm{Mu}-$ nicipal de Acapulco y Estatal de Guerrero en cuanto a la no importancia del nivel de pobreza existente en el puerto el cual es directamente proporcional al ingreso obtenido por el remuneración económica obtenida según el trabajo realizado, es importante visualizar a futuro las problemáticas crecientes dado a la disminución del turismo, misma que afectará e incrementará aún más el nivel de pobreza existente en dicha zona turística del Estado de Guerrero.

\section{Red de drenaje en la Zona Costera de Acapulco e inacción del gobierno municipal}

En el caso de la red de drenaje hasta el año de 1990, se habían realizado grandes trabajos para evitar que los hoteles descargaran sus aguas residuales directamente al mar, sin embargo, hasta la actualidad no se ha concluido dicha situación, esto origina contaminación excesiva en las playas de Acapulco y que ocasionaban a los turistas que se introducen al mar infecciones respiratorias, conjuntivitis, infecciones en la piel como dermatitis, entre otras.

En la actualidad, deberían tener todos los hoteles una red adecuada de drenaje para que no se descarguen sus aguas negras al mar, lo que sin duda genera una disminución importante del turismo nacional y extranjero 
debido al alto grado de contaminación, se le invita al lector a consultar el siguiente video para verificar la información anterior ${ }^{2}$.

En el periodo de 1972 a 1985, Acapulco perdió importancia como centro para vacacionar y se incrementaba aún más el problema de la contaminación misma que en la actualidad persiste; a tal grado que el puerto se ha dado a conocer en muchos Estados de la República Mexicana por dicha problemática sanitaria a lo que el Municipio le ha dado poca importancia (Figura 14).

Figura 14. Imagen de contaminación por basura en la Zona Costera de Acapulco.

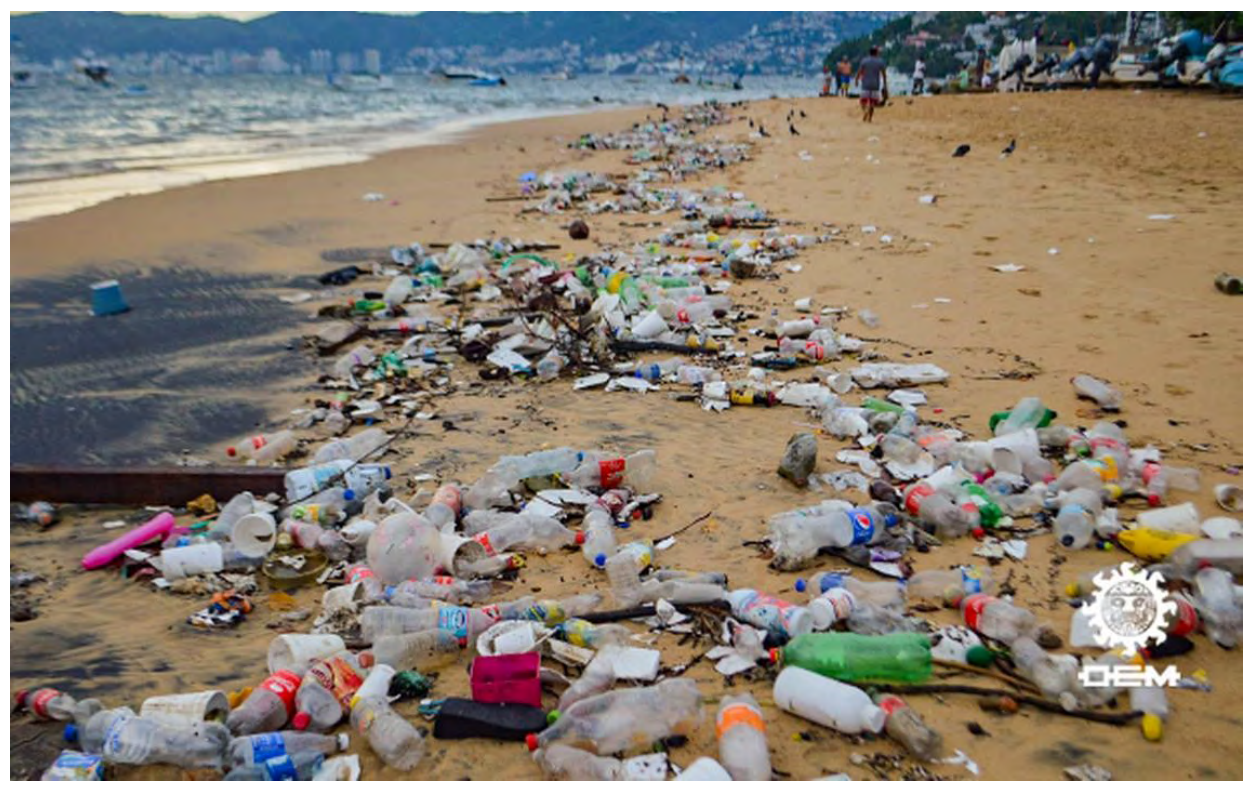

Fuente: Revista en línea El Sol de Acapulco, recuperado de https://www.elsoldeacapulco.com. $\mathrm{mx} /$ local/acapulco-pobre-en-educacion-ambiental-1750634.html, fecha de consulta 9 de mayo del 2020.

Mucha población que vende sus productos sobre la costera de Acapulco aparte de competir con otros destinos turísticos, tiene que competir con la falta de higiene sobre la costera ya que existe poco personal capacitado para la recolección de basura, más aún en temporada alta de

2 Video titulado: Aguas residuales se mezclan con el mar de Acapulco, fecha de consulta 8 de junio del 2020 en https://www.youtube.com/watch?v=8gYW2zWARsc 
vacacionistas el Municipio no toma las medidas sanitarias necesarias para revertir dicha situación, problemática reforzada con las siguientes citas.

"Daño por contaminación significa cualquier perdida o daño fuera de las instalaciones causadas por contaminación, resultante del escape o derrame de petróleo por la instalación, e incluye los costos de medidas preventivas y daños o perdidas posteriores..." (Díaz, 1982, p. 65).

"La alteración de las aguas existe en dos niveles: la del agua potable y la de las aguas salinas de la bahía. Dentro de los que están: Los aceites grasa y petróleo, insecticidas y pesticidas, desperdicios y basura y aguas negras". (Ramírez, 1989, p.154).

En cuanto a al tema de insecticidas y pesticidas existentes en el mar de Acapulco desde el año de 1957, el Consejo Nacional de la Secretaria de Salud para la Educación Palúdica, al realizar una limpieza general en el anfiteatro de la bahía de Acapulco, fue sometido a intensas aplicaciones de Dicloro Difenil Tricloroetano (DDT) mismos que no se depositaron directamente en el mar, sin embargo el DDT se depositó en las partes altas de la geomorfología de la costa de Acapulco, originándose la problemática del acarreo de dichos compuestos químicos nocivos para la salud, ya que en temporada de lluvias el agua al precipitar en la orografía en las partes altas de la Zona Costera de Acapulco por lo que inminentemente el agua corre y busca un cauce natural terminando en las partes bajas en este caso su destino final son aguas oceánicas mismas que corren a lo largo de la costa acapulqueña.

En cuanto a la problemática de las aguas negras e inacción del gobierno municipal ante esta problemática, así como el tema de los desperdicios mismos que terminan en la parte del mar y arena, se evidencian aún más con la siguiente noticia periodística.

\section{Noticia 1.}

En pleno inicio de la temporada vacacional, la Comisión Federal para la Protección contra Riesgos Sanitarios (Cofepris) informó que cinco de las 21 playas de Acapulco, Guerrero, rebasaron el límite permitido de bacterias enterococcus, lo cual es un indicador de contaminación fecal.

Pese a la advertencia, esta semana no han dejado de llegar los vacacionistas a las playas Caletilla, Hornos, Carabali, Manzanillo y Suave, en las costas de Guerrero (INFOBAE, 2019). 
Es muy importante señalar, que la determinación del grado de alteración en este caso de las aguas oceánicas cercanas a la bahía de Acapulco, se rigen actualmente por el Reglamento para la Prevención y Control de la Contaminación de las Aguas sobre todo después de que se detectó la existencia de contaminantes en el puerto de Acapulco, sin embargo, no se respetan estas reglamentaciones por parte de las cadenas hoteleras (figura 15).

Figura 15. Imagen descargas de aguas negras de las cadenas hoteleras vertidas directamente al mar sobre la Zona Costera de Acapulco.

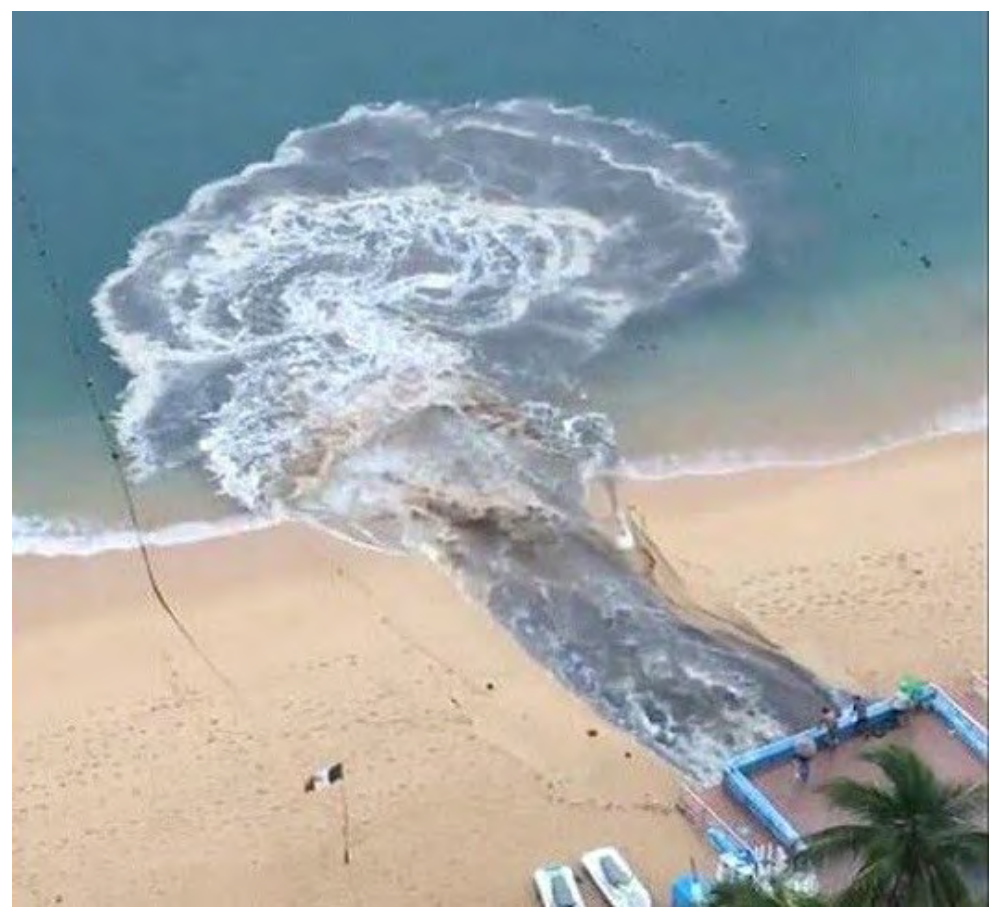

Fuente: Página electrónica Alcanzando el Conocimiento, recuperado de https://alcanzandoelconocimiento.com/conagua-analiza-el-agua-de-la-bahia-de-acapulco-para-determinar-nivel-de-contaminacion-por-vertimiento-de-aguas-residuales/, fecha de consulta 9 de mayo del 2020.

La contaminación en la Zona Costera es muy elevada y perjudicial actualmente, corroborando la información hasta este momento con la siguiente cita. A través de las entrevistas que en 1985 realicé a funcionarios de varias Secretarias implicadas, se refiere que a partir de 1982: Han disminuido levemente los niveles de contaminación, pero la situación básica 
subsiste. En el corto plazo, el gobierno no realizará nuevas obras que mejoren sustancialmente el estado actual de las aguas de la bahía.

La mayoría de los hoteles han conectado sus drenajes al colector de la Costera; algunos cuentan con pequeñas plantas de tratamiento primario de las aguas negras que permiten su reúso. Persisten las descargas clandestinas de aguas negras a la bahía por parte de algunos hoteles y zonas de habitación popular y residencial. A veces falla el sistema de drenaje, es decir se azolva y las descargas se vierten al mar. La planta de tratamiento no se ha construido aun La zona de anfiteatro se está poblando de nuevo; debido a la carencia de drenaje, ello aumenta el fecalismo al aire libre y el arrastre de residuos a la bahía (Ramírez, 1989, p.158).

Con base en la cita anterior y la investigación teórica y empírica en el presente artículo, podemos mencionar que a partir de 1990, el drenaje de los hoteles no es el adecuado hasta la actualidad, y aunque muchas cadenas hoteleras no descargan su drenaje directamente en el mar en la mayoría de los casos todavía persiste esta problemática, de no ser regulada con rapidez esto podría agravarse e incrementarse, incentivando la disminución el turismo año con año.

A continuación, se sustenta y reafirma lo mencionado a lo largo del presente artículo en cuanto a las problemáticas en general acontecidas en el puerto de Acapulco mismas que influyen en la disminución del turismo con la muestra de las siguientes noticias periodísticas recientes.

\section{Noticia 2.}

Acapulco pierde en 5 años $63 \%$ del turismo extranjero por crimen y Guerrero no crece: queda en $0 \%$.

Acapulco tiene una fuerte dependencia del turismo, que en el caso del internacional cayó 63 por ciento entre 2012 y 2017, en tanto que el PIB de Guerrero creció 0 por ciento en ese último año, reportó la agencia Moody's.

La calificadora indicó que Acapulco "es una muestra de cómo el delito puede frenar el turismo".

Enfatizó que la violencia en Guerrero afecta al puerto y que también que ha impactado en la economía de Acapulco las recomendaciones emitidas por el Departamento de Estado de Estados Unidos en la que insta a sus ciudadanos a no viajar a la entidad por sus elevados niveles de criminalidad (Sin Embargo, 2019). 


\section{Noticia 3.}

De acuerdo con datos de la Secretaría de Comunicaciones y Transportes, al cierre de la primera quincena de septiembre del 2010, Acapulco era el octavo puerto que movilizaba, a través de cruceros, más pasajeros (166,796), aunque para igual periodo del 2019, bajó a la décima posición, con 27,971 visitantes, superado por Huatulco y Manzanillo; en dicho lapso de análisis, este indicador disminuyó $83.2 \%$, la caída más pronunciada en el país. Mientras en comparación con el mismo periodo del 2018, Acapulco registra un crecimiento de 10.7 por ciento.

Para Eufemia Basilio Morales, investigadora de la Universidad Nacional Autónoma de México, la caída en los cruceros de Acapulco en los últimos años se debe a la inseguridad que ha vivido todo el estado. Este comportamiento tiene mucho que ver con la inseguridad, lo cual genera menor afluencia turística en los puertos. Esta tendencia se ha seguido desde el 2016, cayendo en 4.8\%", ahondó (El Economista, 2019).

\section{Noticia 4.}

El turismo nacional disminuyó en más de la mitad de los 44 destinos turísticos más importantes del país, entre ellos el puerto, en los primeros meses de la administración del presidente Andrés Manuel López Obrador. De acuerdo con el diario El Universal, entre los sitios con mayor disminución está Acapulco, pues en el primer cuatrimestre de 2019, llegaron 216 mil visitantes menos que en el mismo periodo de 2018.

Le siguen Ciudad de México, que registró una baja de 165 mil viajeros connacionales, Veracruz y Boca del Río, cuyos hoteles alojaron 142 mil mexicanos menos, León y Monterrey. Según cifras del Sistema de Monitoreo Datatur de la Secretaría de Turismo (Sectur), los turistas mexicanos alojados en los hoteles del país disminuyeron a 17 millones 607 mil entre enero y abril del presente año, 503 mil visitantes menos que durante el mismo plazo de 2018 (QUADRATIN, 2019).

\section{Resultados}

Las autoridades del Municipio de Acapulco, deberán proteger y cuidar al turismo que desde el año de 1960 visita el puerto de Acapulco y que aún pese a los factores de disminución presentados y expuestos en el presente artículo sigue visitando dicho puerto mexicano, lo cual es un factor muy importante ya 
Figura 16. Zona costera de Acapulco. Entrevista a turistas nacionales. Datos absolutos, 2020.

¿Cree que la zona costera de Acapulco tiene una imagen rural o urbana?

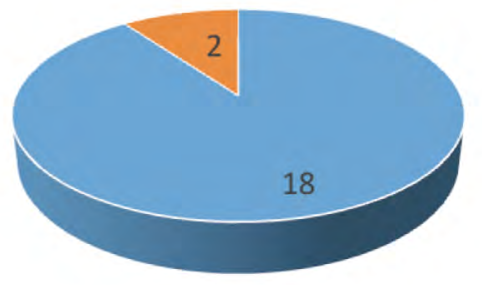

- Imagen urbana Imagen rural

Fuente: Elaboración propia con base en visitas a campo fecha $18 /$ mayo/2020.

Figura 17. Zona costera de Acapulco. Entrevista a turistas extranjeros. Datos absolutos, 2020

$¿$ Cree que la zona costera de Acapulco tiene una imagen rural o urbana?

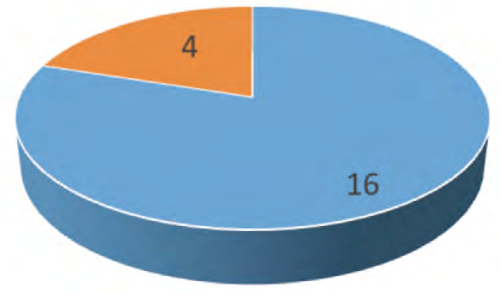

- Imagen urbana " Imagen rural

Fuente: Elaboración propia con base en visitas a campo fecha $24 / \mathrm{mayo} / 2020$. que la mayor parte de los habitantes de la región más del $80 \%$ vive de la economía del turismo y se sostienen en gran parte de esta actividad.

La estructura urbana en cuanto a la instauración de cadenas hoteleras en la Zona Costera, es la que se debió regular tiempo atrás, actualmente se podría generar una gestión o reestructuración urbana con apoyo del Gobierno Municipal y cadenas hoteleras, inclusive algún tipo de estructuración semirural en algunas partes de la Costera Miguel Alemán y colonias al norte de la misma, ya que con base en entrevistas con turistas (figura 16 y 17) mencionan que Acapulco es una ciudad con un alto grado de urbanización, mas no un lugar semirural con atracción dada su naturaleza y geografía.

El tema urbano desregulado impera no solo en el puerto de Acapulco sino en otras zonas costeras en México y del mundo, mismas que podrían llegar a las mismas afectaciones que acontecen hoy en día en el puerto de Acapulco por eso la importancia de una adecuada estructuración urbana, es importante mencionar que la problemática no es directamente del urbanismo es más bien la nula gestión urbana comprendida por las autoridades gubernamentales en cualquiera de sus niveles de 
gobierno, ante lo explicado es momento de reestructurar el puerto de Acapulco y estructurar las colonias aledañas de manera adecuada, profesional y con antecedentes investigativos multidisciplinarios y transdisciplinarios.

Es de gran importancia, comparar al puerto de Acapulco con otros destinos turísticos como Cancún y Puerto Vallarta, los cuales tienen en común el mercado turístico, sin embargo en el caso de Acapulco el inadecuado ordenamiento territorial es más visible derivando en problemáticas políticas, poblacionales, sanitarias y en la marginalidad que sufre el puerto, lo cual trae más afectaciones como inseguridad y violencia en la actualidad dada en gran parte del puerto, reforzando lo anterior con la siguiente cita.

Es de suma importancia, enfatizar que las ciudades turísticas de sol y playa Acapulco, Cancún y Puerto Vallarta alcancen un ordenamiento territorial sustentable, pues de ello depende que permanezcan en el mercado turístico, el cual cada día es más competido. Pero, además, de no hacerlo, corren el riesgo de ser más vulnerables ante los retos que plantea en la actualidad el cambio climático. Para ello es importante la incorporación de ideas y acciones de sus habitantes (Cárdenas, 2016, p.116).

A lo largo del presente artículo, se ha señalado la importancia de tomar en cuenta a los habitantes mismos que conocen en gran proporción el centro vacacional de Acapulco, sin embargo, el aparato gubernamental toma poco o casi nada en cuenta su opinión interpretando que son solo fuerza de trabajo barata, algo que sin duda deberá solucionar el aparato gubernamental municipal.

El presente análisis, no busca una competencia y perjudicar a puertos turísticos en México como Cancún y Puerto Vallarta, puesto que cada uno de ellos tiene sus actividades turísticas, sin embargo, Acapulco cada vez es más vulnerable en diferentes vertientes por la disminución del turismo dado por la inadecuada gestión urbana, contaminación y violencia de cualquier tipo.

Cabe mencionar que, el municipio deberá invertir aún más en el cuidado de sus playas, colocando cestos de basura a lo largo de la Zona Costera, al mismo tiempo mostrar anuncios que inviten al turismo a no contaminar la zona de mar y arena, instaurar más y mejor personal para la recolección de desechos orgánicos e inorgánicos, más y mejores camiones para su captación y lanchas o pequeñas embarcaciones que recolecten la basura que se encuentre flotando en el mar. 


\section{Discusión de Resultados y Reflexión}

Hace más de 40 años, el puerto de Acapulco se ha dado a conocer a nivel nacional e internacional por la falta de higiene y la ausencia del cuidado en sus playas, de no invertir tiempo, dinero, gestión, regulación, coordinación, concientización en los habitantes y turistas, es cuestión de tiempo la decadencia del puerto de Acapulco.

Por otro lado, es importante que el Municipio regule, implemente y aplique las normas ya existentes para el cuidado de sus playas, en este caso la prohibición del descargue de contaminantes y aguas negras por parte de las cadenas hoteleras, fomentando que ellas mismas generen una red de drenaje adecuada para que sus desperdicios no desemboquen en el mar.

Una posible solución a la problemática anterior es la gestión y coordinación entre el Municipio y las grandes cadenas hoteleras para minimizar la gravedad de la contaminación, ya que dichos hoteles anualmente obtienen ganancias muy elevadas debido al uso de las playas en México las cuales con base en ello deberán tener personal capacitado de recolección de basura o limpieza sobre la playa, personal apto para emergencia en este caso salvavidas, para que con estas medidas se vean beneficiadas las cadenas hoteleras, turistas, el puerto de Acapulco y con ello sus habitantes.

Así mismo la parte del muelle de Petróleos Mexicanos (PEMEX), Base Naval y el Club de yates, deberán tener cuidado con los desperdicios que generan para no arrojarse directamente al mar y que se busquen vías alternas para que los contaminantes no afecten a la zona costera con algún tipo de tratamiento a sus desperdicios.

En el caso de la inseguridad en sus diferentes vertientes el Municipio de Acapulco, deberá proporcionar una mayor seguridad al turista en su estancia en la playa, colocando más personal de seguridad debidamente capacitado y constantemente se vigile al turismo en caso de violencia ejercida por diversos grupos delictivos, sin embargo esto solo deberá ser por un tiempo determinado, ya que el tener en todo momento y lugar a elementos de seguridad nacional como lo puede ser policía Municipal, policía Federal, Marina, Ejercito, Guardia Nacional, entre otras, podría ser contraproducente, ya que el turismo pasado un tiempo podrá pensar que Acapulco siempre es y será un destino turístico inseguro.

Por lo anterior se deberá gestionar un plan de cuidado por parte del Gobierno Federal, Estatal y Municipal orientado a los habitantes en general 
para después ser replicado en los turistas y así pueda regresar la seguridad al puerto de Acapulco de manera gradual.

Por otro lado, de igual manera en el tema de seguridad y/o violencia en menor proporción en cuanto al robo de pertenencias por parte de los habitantes a turistas, podría desaparecer, colocando personal de vigilancia por parte del Municipio sobre la Zona Costera para que esté constantemente vigilada y los habitantes que se dedican a delinquir no lo sigan realizando.

El tema de la ola de violencia que actualmente vive el puerto, es un tema demasiado delicado inclusive se puede observar y constatar con a la siguiente cita.

Mientras que el año de 1991, fue para Acapulco uno de los más pacíficos en términos de homicidios en los últimos 25 años, en los últimos cinco no se ha convertido en la ciudad más violenta del país. ¿Cómo ocurrió ese cambio? Durante el citado año en Acapulco se registraron, en todo el año, 80 homicidios. Para 2012, la cifra se multiplicaría casi dieciséis veces, cuando ocurrieron 1,271 casos... (Peña, 2017, p.24-25).

Es urgente, atender la problemática de homicidios en el Puerto de Acapulco, actualmente internacionalmente el puerto es visto como inseguro, insalubre y con poca vista natural y más aun enfocándonos solo en los homicidios que se dan por diversas circunstancias, es el trabajo y gestión del gobierno Federal, Estatal y Municipal responsables de otorgar seguridad al turismo y al habitante, solo así el puerto de Acapulco podrá incrementar la afluencia de vacacionistas en un futuro.

Por último, el tema de la Pandemia de COVID-19 que significativamente aconteció en el puerto de Acapulco, México y en el mundo, amplió la disminución del turismo, es por ello que las medidas de sanidad deberán de estar presentes hasta que dicha pandemia desparezca por completo, por otra parte siempre deberá existir en todo momento higiene por parte de los habitantes que venden sus productos en la Zona Costera, generando una coordinación entre el Sistema de Salud en cualquiera de sus niveles de gobierno con los habitantes, capacitándolos de alguna manera en materia de sanidad y limpieza para que el turista pueda estar seguro de la calidad de los alimentos vendidos por los habitantes.

Pues, de no generarse medidas urgentes para evitar la disminución del turismo en Acapulco, muy probablemente el puerto estará viviendo sus últimos 
momentos como lugar de visita y estadía para vacacionar, ocasionando un posible colapso y desaparición del puerto en un futuro no muy lejano.

\section{Referencias}

Acapulco de Juárez. (2020). Derrama económica de 287 millones de pesos dejó el "puente" en Acapulco. Periódico en línea H. Ayuntamiento Constitucional de Acapulco. México. Recuperado https://acapulco. gob.mx/2020/02/derrama-economica-de-287-millones-de-pesos-dejo-el-puente-en-acapulco/

Cárdenas, E. (2016). Crecimiento y planeación urbana en Acapulco, Cancún y Puerto Vallarta. Revista Investigaciones Turísticas, $n^{o}$ 12, pp. 99-120. España. Recuperado http://dx.doi.org/10.14198/ INTURI2016.12.05

De la Torre, M \& Navarrete, D. (2013). Turismo, violencia y vulnerabilidad. Editorial KAIROS. Revista de Temas Sociales. Argentina. (p.3). Recuperado https://dialnet.unirioja.es/descarga/articulo/4349553.pdf

Del Valle Pérez Colmenares, S. (2017). La planificación y prevención de los impactos ambientales del turismo como herramienta para el desarrollo sostenible: Caso de estudio Timotes, Venezuela. Revista interamericana de ambiente y turismo, 13(2). Chile. (p. 164) Recuperado https://dx.doi.org/10.4067/S0718-235X2017000200164

Díaz, L. (1982). Responsabilidad del estado y contaminación. Editorial Porrúa, México.

El Economista. (2018). Acapulco y Tlaxcala, con el peor mercado laboral del país, Periódico en línea EL ECONOMISTA, CDMX. México. Recuperado https://www.eleconomista.com.mx/estados/Acapulco-yTlaxcala-con-el-peor-mercado-laboral-del-pais-20180824-0014.html

El Economista. (2019). Acapulco registra la mayor caída en cruceros a nivel nacional. Periódico en línea EL ECONOMISTA, CDMX. México. Recuperado https://www.eleconomista.com.mx/estados/ Acapulco-registra-la-mayor-caida-en-cruceros-a-nivel-nacional-20191008-0029.html

Guerrero, M., Santiago, A., Bouza C. (2009). El mercado turístico de Acapulco: estudio del perfil de los turistas. Editorial REDMARKA UIMA-Universidad de A Coruñ-CIECID, Argentina. (p.78). Recuperado https://dialnet.unirioja.es/descarga/articulo/4128654.pdf 
INFOBAE. (2019). Así se ven las playas de Acapulco invadidas por contaminación fecal. Periódico en línea INFOBAE. Argentina. Recuperado https://www.infobae.com/america/mexico/2019/07/09/asi-seven-las-playas-de-acapulco-invadidas-por-contaminacion-fecal/

López, R., Rodríguez A., Barragán C., Castellanos C., Palacios R. \& Martínez. (2012). Turismo y contaminación ambiental en la periferia urbana de Acapulco: Ciudad Renacimiento. Editorial El Periplo Sustentable. Universidad Autónoma del Estado de México, México. (p.1). Recuperado de: https://www.redalyc.org/articulo. oa? id=1934/193424449006

Mombelli, M. (2011). Espacios rurales y espacios urbanos. Constantes y cambios en el uso del suelo. Revista Geográfica de América Central,47E(2), 1-19. Costa Rica. https://www.revistas.una.ac.cr/ index.php/geografica/article/view/3156

Orgaz Agüera, Francisco, \& Moral Cuadra, Salvador. (2016). El turismo como motor potencial para el desarrollo económico de zonas fronterizas en vías de desarrollo: Un estudio de caso. Editorial El periplo sustentable. Estado de México, México. (p.3). Recuperado de: http://www.scielo.org.mx/ scielo.php?script $=$ sci_arttext\&pid=S1870-90362016000200008\&lng= es\&tlng=es.

Peña, R. (2017). La ciudad de Acapulco. Análisis de los caminos de la violencia y crimen en México. Rev. Est. de Políticas Publicas, 3(2): junio - noviembre 2017, pp. 20-32. Santiago de Chile. Recuperado https://dialnet.unirioja.es/descarga/articulo/7387855.pdf

Programa Regional Acapulco. (2016). Acapulco Guerrero México. http://i. guerrero.gob.mx/uploads/2019/10/Programa-Regional-Acapulco-2016-2021.pdf

QUADRATIN. (2019). Baja llegada de turismo nacional a Acapulco en primeros meses de 2019. Periódico en línea QUADRATIN, Chilpancingo Guerrero. México. Recuperado https://guerrero.quadratin. com.mx/baja-llegada-de-turismo-nacional-a-acapulco-en-primerosmeses-de-2019/

Ramírez, J. (1989). Turismo y Medio Ambiente: El caso de Acapulco. Editorial Universidad Autónoma Metropolitana, México. Recuperado de: https://estudiosdemograficosyurbanos.colmex.mx/index.php/ edu/article/view/651/644 
Schiebler, S., Crotts, J. \& R. Hollinger. (1996). Florida Tourists Vulnerability to Crime. In Tourism, Crime and International Security Issues. Chichester: Wiley, Inglaterra, pp. 35-70.

Sin Embargo. (2019). Acapulco pierde en 5 años 63\% del turismo extranjero por crimen y Guerrero no crece: queda en $0 \%$. CDMX. Periódico en línea Sin Embargo México. Recuperado https://www.sinembargo. $\mathrm{mx} / 07-03-2019 / 3547045$

Solís, M., Hernández, L. \& Villagómez, J.(2016). El Valor Percibido del Destino Turístico en Relación con el Perfil del Turista en Acapulco, Guerrero-México. Editorial Investigación administrativa, 45(118). Instituto Politécnico Nacional.México. (p.2). Recuperado de: http://www.scielo.org.mx/ scielo.php?script=sci_arttext\&pid=S2448-76782016000200002\&lng= es\&tlng=es. 
